\title{
Desde la hermenéutica filosófica de Martin Heidegger al ser docente militar
}

\author{
From the philosophical hermeneutics of Martin Heidegger to being \\ a military teacher
}

\author{
Janett J. Zerpa Higuera \\ janettzerpa01@gmail.com \\ Universidad Militar Bolivariana de Venezuela
}

Recibido: 12-07-2016 / Revisado: 18-07-2016 / Aceptado: 11-09-2016 / Publicado: 09-01-2017

\begin{abstract}
RESUMEN
El estudio se enfoca en el ser docente militar a partir de la pregunta del ser de Martin Heidegger. Se hace necesario preguntarse por el "Es": quién es ese sujeto y objeto del conocimiento y cómo se devela ante sí y ante los otros. Heidegger, a través de su hermenéutica filosófica y los estudios fenomenológico -hermenéuticos del "Ser" abren el camino para adentrarse en ese mundo que determina al Ser, que en este caso busca su autodefinición como pedagogo, y especialmente el docente militar. El docente construye conocimiento, y se encamina no sólo a su búsqueda, sino que es agente de su transmisión $\mathrm{y}$ transformación. Por ello, es inminente preguntarse por su ser, qué lo determina, cuál es su esencia y cómo fluye e influye ese ser en su develación ante sí y ante los otros, cómo muestra ese conocimiento al desocultar ese ser innato. Martin Heidegger (1993) en Ser y Tiempo aborda el estudio ontológico del ser donde sostiene que el pensamiento en tanto una reflexión meditativa y consciente, no busca al Ser porque pensar y Ser es de hecho lo mismo. Señala que la pregunta por el sentido del Ser, se aborda a partir de la pregunta por el SER, en la que el hombre es tanto el preguntador como el preguntado y acontece en la analítica de la existencia humana, pues en ella se llega a la luz. La pregunta, el conocimiento previo (producto del existir en un mundo del ser - ahí) y la respuesta dan como resultante la definición del ser que se hace aparente ante el ente y es fuente del conocimiento. Es la búsqueda, a través del preguntar por el ser del docente militar, es a su vez, la búsqueda también de la identificación de la pedagogía militar, su comprensión y cómo construye el conocimiento. El ser docente entonces envuelve no sólo el determinarse a sí mismo sino comprenderse para ser, conocer y hacer.
\end{abstract}

Palabras clave: Estudios, Ser de Heidegger, docente, pedagogía militar
The study focuses on being a military teacher based on the question of the being of Martin Heidegger. It is necessary to ask for the "Is": who is that subject and object of knowledge and how it reveals itself and to others. Heidegger, through his philosophical hermeneutics and the phenomenological studies -hermeneutics of "Being" open the way to get into that world that determines being, which in this case seeks its self-definition as a pedagogue, and especially military teachers. The teacher builds knowledge, and is directed not only to his search, but is an agent of its transmission and transformation. It is therefore imminent wonder his being, which is determined, what its essence and how it flows and influences that being in his unveiling to himself and to others, how to show that knowledge to uncover the innate being. Martin Heidegger (1993) in Being and Time addresses the ontological study of being where he holds that thought as a meditative and conscious reflection, does not seek the Being because thinking and Being is in fact the same. Notes that the question of the meaning of Being, is approached from the question of being in which man is both the questioner and the questioned and occurs in the analytic of human existence, for in it you get to the light. The question, the prior knowledge (product of existing in a world of being there) and the response give as a result the definition of being that becomes apparent before the entity and is the source of knowledge. It is the search, by asking for the being of the military teacher, is in turn, the search also for the identification of military pedagogy, its understanding and how it builds knowledge. Being a teacher then involves not only determining oneself but understanding oneself to be, to know and to do.

Key words: Studies, Being of Heidegger, teacher, military pedagogy 
INTRODUCCIÓN

tiempos hemos venido enfatizando el centro de estudio de la Pedagogía como la ciencia de la educación, de la formación del ser humano, de la praxis educativa. Por tanto, el pedagogo ejerce su profesión en el ámbito de la praxis educativa, pues la pedagogía hace énfasis en su objeto como praxis.

En tal sentido, Molins (2005) refiere que la pedagogía como ciencia tiene entre sus principios la educabilidad o capacidad del ser humano de educarse; la educatividad o la capacidad de personas para educar a otro; los fines o propósitos del proceso educativo; la pasión o cualidad que refiere a la voluntad, amor y vehemencia para alcanzar los fines; la racionalidad o sea la capacidad humana para tomar decisiones acorde al contexto social y su ideología; el arte, es decir la creatividad en la teoría y praxis educativa y finalmente enfatiza el principio de ciencia, o sea, su sistematización. No se observa un acercamiento al ser del educador entre los principios de Molins, sólo en la caracterización o cualificación en la pasión, arte y racionalidad se asoma algo al ser, mas no se establece el ser de quién.

Otros ven a la pedagogía a través de sus fines. El docente es aquel que se forma para un contexto determinado, para un fin y una ideología. Es Gadamer (1977), inspirado en Heidegger, quien se acerca a través de su definición del ser histórico a la idea del ser humano en su proceso de ser por el comprender en su historia. Flores (2000) por su parte, señala que toda pedagogía es un resultado histórico, efecto de la tradición y que la dinámica educativa se da en un tiempo, cultura y sus interacciones entre estudiante y el objeto de estudio.

Lo anteriormente expresado vislumbra una tendencia a enfatizar el estudio de la pedagogía en tanto a fines y praxis; pero demuestra un interés residual en la investigación que aborda el ser docente y su profunda influencia en el ser superando el hacer educativo. Los estudios se enfocan en su formación como docente universitario y el
A través de los currículo que le debe ser propio (Olmos: 2009); en su hacer. Sin embargo; se hace necesario preguntarse por el Es: quién es ese sujeto y objeto del conocimiento y cómo se devela ante sí yante los otros. Heidegger, a través de su hermenéutica filosófica y los estudios fenomenológico-hermenéuticos del ser abre el camino para adentrarse en ese mundo que determina al ser, que en este caso busca el Ser del pedagogo, y especialmente el docente militar.

\section{El Ser desde Heidegger y la pregunta del Ser}

El docente construye conocimiento, y se encamina no sólo a su búsqueda, sino que es agente de su transmisión y transformación. Por ello es inminente preguntarse por su ser, qué lo determina, cuál es su esencia y cómo fluye e influye ese ser en su develación ante sí $\mathrm{y}$ ante los otros, cómo muestra ese conocimiento al desocultar ese ser innato. Martin Heidegger (1993) en Ser y Tiempo aborda el estudio ontológico del ser donde sostiene que el pensamiento en tanto una reflexión meditativa y consciente, no busca al Ser porque pensar y Ser es de hecho lo mismo.

La pregunta por el sentido del Ser, en la que el hombre es tanto el preguntador como el preguntado, se da en la analítica de la existencia humana, pues en ella se llega a la luz. Heidegger sostiene que preguntar por el Ser es comprenderlo. La esencia del hombre radica en estar en correspondencia con el ser del ente. Se accede al Ser a través de su comprensión, pues ella misma es una determinación del ser- ahí (Dasein) cuando el ser toma conciencia de sí en cuanto Ser.

Este filósofo sostiene que el ser es su comprender y este comprender no indica una manera de proceder del sujeto, sino el modo del ser mismo del ser- ahí. El Ser de Heidegger es para la razón, lo presente ante el conocimiento, lo constante y lo estático. Se entiende que, en este caso, el presente es lo que acontece SIEMPRE, lo que está presente. 
En oposición al devenir pasajero (a lo que está por venir o lo cambiante).

Desde la perspectiva de Martin

Heidegger, según Waldenfels (1997)

"la fenomenología hermenéutica, accede

al conocimiento a través del Dasein (el ser-ahí) que en la interpretación del sentido transforma la comprensión previa en una comprensión expresa del ser y de su auto-comprensión".

La Sociedad Interamericana de Estudios Heideggerianos (2012) presenta la estructura formal de la pregunta del ser de Heidegger, señalando que, para el filósofo, "el preguntar mismo tiene, en cuanto a comportamiento de un ente - del que pregunta- su propio carácter de ser". Es decir que la pregunta devela o contiene a quien pregunta. Además, señala que "la comprensión... puede estar... impregnada de teorías y opiniones tradicionales acerca del ser..." por consiguiente se sostiene que para elaborar una pregunta por el ser significa hacer que un ente (el que pregunta) se vuelva transparente en su ser. Es decir que quien pregunta se devela ante sí, ante su ente como ser.

Ante la pregunta del ser, todo preguntar es un buscar, todo buscar tiene una dirección previa que le viene de lo buscado (precompresión). Preguntar es buscar qué es y cómo es un ente. La acción de preguntar incluye lo preguntado, aquello a que se pregunta y lo que se busca con la pregunta (Heidegger: 1993). Para él, cuando alguien pregunta conscientemente, también sabe cuál es el objeto de su búsqueda, pues sin este conocimiento, previo a la obtención de la respuesta, toda pregunta carecería de sentido.

A lo preguntado Heidegger le llama conocimiento anterior o conocimiento previo, lo cual a su vez incluye una pre-suposición epistémica en el proceso de la interrogación. Se hace la formulación de la pregunta sabiendo de antemano la respuesta o sabiendo lo que pretende conocer a través de ella. Es entonces cuando la respuesta tiene sentido, pues ella refiere a la naturaleza del ser por el que se pregunta. La pregunta, el conocimiento previo (producto del existir en un mundo del ser-ahí) y la respuesta dan como resultante la definición del ser que se hace aparente ante el ente y es fuente del conocimiento.

A través de los estudios heideggerianos se accede al conocimiento del ser, el principio y esencia de las cosas, los valores, la moralidad, la ética válida para los seres humanos. El estudio del ser docente busca entonces su esencia y ser a partir de su concepción de sí y su develación en el ente en su existencia como ser docente. Siendo y existiendo encuentra su ser $\mathrm{y}$ en su existencialidad, su ser docente cobra sentido.

Desde Heidegger, desde su perspectiva fenomenológica, se accede y se determina lo ontológico, pues se hacer ver desde sí mismo aquello que se muestra y se deja ver tal como se muestra a sí mismo. El significado es atribuido al principio de las cosas, a las cosas mismas, por sí mismo.

Autores, investigadores, pensadores del siglo XX tales como Gadamer, Derrida, Paul Ricoeur, Vattimo, entre otros, han sido en gran medida influenciados en sus estudios, por la filosofía de Heidegger. Hoy día muchos otros se han embarcado en los estudios del ser desde su perspectiva. Las cátedras en prestigiosas universidades del mundo, aparición de sociedades científicas dedicadas a poner en práctica estudios del ser, le dan vigencia y constituyen un aporte a la comprensión de la sociedad postmoderna. Muchas publicaciones y autores promulgan el pensamiento y la praxis de los estudios, la filosofía Heideggeriana entre los que se encuentran Vigo, Rodríguez, Bertorello y Xolocotzi entre otros. Todo ello da fe que el estudio del Ser del docente está cada vez más vigente y emprender este camino proporciona una fundamentación para teorizar, crear una filosofía y dar cuenta de la concepción de pedagogía y la educación actual.

Estudios recientes como el de Villarreal Hernández (2014) en Venezuela, se orientan a la determinación del ser docente universitario, pero a través de su hacer. 
Describe el hacer del facilitador traducido en docencia y su impacto a la tarea educativa desde la investigación y extensión.

Es necesario un estudio fundamentado en Heidegger que busque la identificación del Ser a partir de su comprensión de Sí, de su existencialidad en el mundo. Sólo a partir de esa autocomprensión y autoconciencia de sí, de su finitud en el tiempo, se determina el ser del docente y sus implicaciones en una filosofía educativa que dé respuesta a las necesidades de una educación con sentido.

\section{El Ser del docente militar desde Heidegger}

La naciente pedagogía militar, en su proceso de construcción y sistematización está a la búsqueda de identificar aquellos elementos que fortalecen su sistematización como ciencia, arte, y filosofía educativa. Indudablemente que entre esos elementos de identificación y determinación de su esencia se encuentra un actor del proceso académico que lo constituye el docente militar y civil que hace vida en su contexto existencial, histórico, social, cultural, ecológico, ideológico castrense.

Cabe preguntarse, ¿cuánto sabemos de ese ser, ¿qué lo identifica como docente militar? ¿Se está a la búsqueda, de preguntar y responder esa pregunta que da cuenta del ser docente o pedagogo militar, aquél que, a decir de Heidegger, nos da razón de su ser? Es necesario abordar la pregunta del ser docente militar, de desocultar su preconcepción y precomprensión de Ser, que se da en su existencialidad y su historicidad o el mundo de la educación militar; ese Ser que se desoculta y sale a la luz en respuesta a esa pregunta que no es otra cosa que el ser mismo. Es la búsqueda, a través del preguntar por el ser del docente militar, la búsqueda también de la identificación de la pedagogía militar; su comprensión y cómo construye el conocimiento. A decir de Heidegger, se accede al conocimiento mediante la interpretación de la auto comprensión y de la comprensión humana del Ser. El conocimiento no se distancia del ser porque toda comprensión autentica es constitutiva de la praxis del interprete, es decir constituye al interprete. (Barros:1989).

Cuesta (1991) señala que la filosofía de Heidegger, el Dasein (ser ahí) o ser del hombre. Se define como ser viviente que en esencia es aquel que tiene la facultad de hablar. Así que el Ser se muestra o permite ver al que habla, a los que hablan con otros, en la medida que permite verlo (al Ser), descubrirlo como no oculto.

Para Heidegger, el Ser se pregunta por el ser cuando empieza a interrogarse por el ser ahí, que es el ser que existe en el modo del comprender el ser. La comprensión para Heidegger, no es solo conocimiento, sino un modo de Ser que existe comprendiendo. La comprensión está determinada por el ser en el mundo en donde se actualiza el Dasein, dentro de un contexto de significados. Ese Ser en el mundo que supone el horizonte de un mundo que progresa siempre en la dimensión del tiempo que está abierto al futuro.

Para Heidegger, toda comprensión del mundo comporta la existencia y toda interpretación que atañe a la comprensión tiene que haber comprendido ya aquello que intenta interpretar. El lenguaje, como la casa del ser, es el acontecer en el que primeramente se abre para el hombre el ente como ente (pues se muestra el ser del ente). Él habla, abre surcos en el campo del ser. Se hace visible o se muestra la claridad del fenómeno, se deja aprehender debido al desocultamiento.

Para Barros (1989) Heidegger presenta al ser como arrojado en el mundo, tal que somos seres que así comprendemos y ese comprender no es sólo un tipo de actividad propia de un sujeto, sino que sustenta todas las actividades. El ser docente entonces envuelve no solo en determinarse a sí mismo sino comprenderse para ser, primeramente, $y$ luego conocer y hacer.

El mandato de la UNESCO (1988), plantea dentro de sus retos del milenio, que la educación se sustenta en cuatro pilares: el aprender a conocer, aprender a hacer, 
aprender a convivir y aprender a ser, siendo este último el que representa un reto para el siglo XXI. En este sentido, el ser del docente. Cobra gran importancia y apuntala hacia la consecución de las metas propuestas. Es necesario embarcarse en un estudio del ser docente universitario específicamente, el ser docente militar para consolidar una filosofía educativa y dar sentido a una pedagogía militar, la cual se está haciendo, se está tratando de comprender, pero que, sin aclararse quién es, no podrá tener éxito; pues en el comprenderse Ser, conocer y hacer se da la educación que exige la comunidad castrense y nacional.

\section{CONCLUSIONES}

La autora considera que la idea del Ser esta en la mente (en el ideario) de la persona y se refleja en sus actos, en sus relaciones con los otros $\mathrm{y}$ en su lenguaje $\mathrm{y}$, en sus interpretaciones de sí mismo. No se ha abordado hasta este momento un estudio que permita aflorar estos imaginarios, concientizarlos $y$ hacerlos naturalmente demostrados en el hacer cotidiano de la praxis docente militar. Si estamos en proceso de construcción de la pedagogía militar es hora de girar la vista hacia uno de los actores del acto pedagógico, el Ser docente, que sustente y fortalezca esta nueva concepción pedagógica. Es necesario caracterizar y teorizar sobre quién enseña y quién investiga en la docencia militar, sus competencias, sus valores y sus acciones en pro de la consecución de los fines de la educación militar, del desarrollo de las potencialidades docentes y de su impacto en la educación venezolana.

\section{REFERENCIAS}

Barros, Nicolás (1989) Hermenéutica, Filosofía práctica y Ciencias Humanas. Cuadernos Venezolanos de Filosofía. № 01. Año I. Junio 1989. Caracas: Universidad Católica Andrés Bello. pp 33-45.
Cuesta A, José M. (1991) Teoría Hermenéutica y Literatura. Madrid: Vigor Distribuidores, S.A.

Flores, R. (2000) Hacia una Pedagogía del Conocimiento. Bogotá: McGrraw-Hill Interamericana, S.A.

Gadamer, H. (1977) Verdad y Método: Fundamentos de una Hermenéutica Filosófica. Salamanca: Sígueme.

Heidegger, Martin (1993) El Ser y el Tiempo. Chile: Editorial Universitaria. Colección el Saber y la Cultura.

IESALC-UNESCO, (2008). Conferencia Regional de Educación Superior.

Disponible en http://www.iesalc.unesco.org.ve/index.ph p Consulta: 3/04/2016.

Molins, M. (2005) Pedagogía: Ciencia de la Praxis Educativa. Caracas: Fondo Editorial de Humanidades y Educación, Universidad Central de Venezuela.

Olmos de Montañez, Oly (2009) Alguna Ideas Para La Reconceptualización De La Pedagogía Como Fundamento De La Formación Docente. Maracay: vol. 30.n.1 junio 2019.

Sociedad Interamericana de Estudios heideggerianos (2012) Ser y Tiempo: Introducción, Capítulo Primero. www.sociedadheidegger.org. Consulta mayo 302016.

Villarreal Hernández Jesús A. (2014) Episteme Teorético desde el Ser de la Docencia Universitaria. Valencia: ARJÉ Revista de Postgrado FACE-UC. Vol. 8 № 14. EneroJunio 2014. Edición Especial / 247-270.

Waldenfels, Bernhard (1997) De Husserl a Derrida. Introducción a la FenomenologíaBarcelona: Paidós. pp 5962. 